\title{
Cross Sectional Study on Characteristics of Bipolar Disorder Association with Alcohol Dependence in a Tertiary Care Center in South India
}

\author{
B.Bhuvaneshwaran ${ }^{1 *}$, R. Kumar ${ }^{2}$
}

\section{ABSTRACT}

Bipolar disorders are commonly associated with other psychiatric disorders, which influence the course, severity and outcome of the disorder Aim: to study the association of alcohol dependence on bipolar disorder and to compare bipolar patients without alcohol dependence in tertiary care center in south India Methods: A total of 83 patients with age of 18-65 years who were admitted in the acute in-patient ward of the Institute of mental Health were administered M.I.N.I PLUS neuropsychiatric interview module and the patients who fulfil the diagnostic criteria for BPAD after ruling out the secondary causes of mood disorder were included in the study. The scales utilized to study the alcohol dependence association with bipolar disorder are in the form of illness variables and symptoms severity. Results: GroupA $(n=42)$ patients with bipolar disorder and co-morbid alcohol dependence and group-B $(\mathrm{n}=41)$ patients with bipolar disorder without alcohol dependence (Group-B) was noted in our study. Strong positive correlation between severity of alcohol dependence score and YMRS score, functioning score, positive scale of PANSS and aggression scores noted and Only treatment adherence, family H/o BPD and family H/o alcohol dependence show significance in the present study. Conclusion: Increase in severity of alcohol dependence is associated with severity of Bipolar disorder.

Keywords: Alcohol, Bipolar, Depression, Mania

Bipolar disorder (BPD) is a severe and persistent psychiatric illness affecting $1.3 \%$ to $1.7 \%$ of population [1,2]. It is an episodic illness characterised by the occurrence of manic or depressive episodes. Alcohol dependence rather than alcohol abuse causes changes in neuronal plasticity of different brain circuits which leads to alteration in neuronal transmission causing various psychiatric manifestations [2,3].Alcohol induced mood disorder

\footnotetext{
1 (Assistant Professor, Department of Psychiatry, Government Medical College, Thoothukudi, Tamilnadu, India) ${ }^{2}$ (Professor and Head, Department of Psychiatry, Sri ManakulaVinayagar Medical College and Hospital, Puducherry, India) *Responding Author
}

Received: August 17, 2017; Revision Received: November 02, 2017; Accepted: November 23, 2017

(C) 2017 B. Bhuvaneshwaran, R. Kumar; licensee IJIP. This is an Open Access Research distributed under the terms of the Creative Commons Attribution License (www.creativecommons.org/licenses/by/2.0), which permits unrestricted use, distribution, and reproduction in any Medium, provided the original work is properly cited. 


\section{Cross Sectional Study on Characteristics of Bipolar Disorder Association with Alcohol Dependence in A Tertiary Care Center In South India}

with manic or depressive features has its onset during intoxication or withdrawal and results from the pharmacological effects of alcohol. A significant minority of substance abusers exhibit persistent symptom states that may signal the presence of a comorbid mood disorder [4,5].The presence of alcohol dependence and BPD together is called dual diagnosis and it poses difficulties in both diagnosis as well as the treatment of these conditions. Both disorders have detrimental effects on each other's course and affects the treatment [3]. Very few studies analyzed BPD and alcohol dependence alone and alcohol induced mood disorder were not excluded [6].Indian studies are particularly lacking in this context. The present study was undertaken to study the impact of alcohol dependence on course, severity and outcome of bipolar disorder.

\section{MATERIALS AND METHODS}

A total of 83 patients with age of 18-65 years who were admitted in the acute in-patient ward of the Institute of mental Health either with manic or depressive or mixed episodes were administered M.I.N.I PLUS neuropsychiatric interview module[7]and the patients who fulfill DSM IV TR diagnostic criteria for both bipolar disorder and alcohol dependence (group A) or patients who fulfill the criteria for bipolar disorder alone (comparison group B) after ruling out the secondary causes of mood disorder were included in the study. Specific questionnaires and rating scales like patients having either manic episode with YMRS>20,or depressive episode with HAM-D>15 or Mixed episode at baseline were administered once the patients were initially stabilized after admission. Details about the entire illness were obtained from the informant as well the patient after a detailed semi structured interview following a pattern similar to Life Chart Method for assessing Bipolar Disorder to get a comprehensive view about the entire period of illness. Mood disorders due to general medication, substance induced mood disorders, co morbid seizure disorder, and mental retardation are excluded under our study. The approval of the Institutional Ethical committee was obtained before conducting the study. Patients were taken up for the study after obtaining written and informed consent from both the patient and the informant.

\section{RESULTS}

Out of 83 patients group-A (n=42)patients with bipolar disorder and co-morbid alcohol dependence and group- $\mathrm{B}(\mathrm{n}=41)$ patients with bipolar disorder without alcohol dependence (Group-B) was noted in our study. There is no significant difference in age, educational status and socio demographic parameters between the groups. We have observed significant difference between two groups with regards to treatment adherence by using eleven item rating scale for evaluation of patient recognition of the illness, family history of alcohol dependence and current nicotine dependence. Patients in group A have poor treatment adherence and have significant history of alcohol dependence when compared to patients in group B. But there is no significant association in family history of BPDs among the two groups(Table-1).Comparison of continuous illness parameters among two groups only 3 of the 10 variables show significant difference between the two groups. i.e) BPD patients with alcohol dependence have significant difference in the duration of episode, remission period 


\section{Cross Sectional Study on Characteristics of Bipolar Disorder Association with Alcohol Dependence in A Tertiary Care Center In South India}

and total number of life time hospitalisations when compared to BPD patients without alcohol dependence(Table-3).Association of certain symptom severity scores between the two groups due to average hospitalization for patients in acute care ward was 3 weeks in our institute and 50\% response to the treatment was usually observed clinically within 2 weeks particularly in patients admitted with severe symptoms. YMRS scores at baseline and 2 weeks, scores of positive subscale of PANSS at base and 2 weeks, functioning assessment score at baseline and insight at baseline and aggression score at baseline are significant between the 2 groups. HAMD scores, insight and functioning scores at 2 weeks and suicide intent score does not show significance between the 2 groups (Table-2).Strong positive correlation between severity of alcohol dependence score and YMRS score, functioning score, positive scale of PANSS and aggression scores(Table-4).The difference between the mean scores at the baseline and 2 weeks is calculated. These mean differences in scores indirectly assess the treatment response at the end of two weeks after hospitalization due to the less number of patients completing 4 weeks admission and difficulty in follow up the discharged patients due to the cross sectional study. By comparing the mean difference in the scores we are predicting responds better to treatment. There is significant difference in treatment response between the two groups with respect to YMRS scores, HAMD, functioning and insight score. The difference in the psychosis and aggression scores does not show significance between the groups and it is inferred that patients in group B improve faster than group a patients. Multiple logistics regression was performed with alcohol dependence as independent variable and various illness parameters and symptom scores as dependent variable. Only treatment adherence, family H/o BPD and family H/o alcohol dependence show significance. We are able to infer that alcohol dependence predicts 5.78 odds of having family H/o BPD and 44.17 odds of having family H/o alcohol dependence and have only 0.03 odds for treatment adherence.

\section{DISCUSSION}

The variables like marital status, religion, occupation, socioeconomic status between the two groups. Group A 59.5\% were married when compared to 70.7\% in group B and most of the patients belong to Hindu religion and were doing semiskilled work and belong to low socio economic status in both the groups. The results of socio demographic parameters are not significant and are in agreement with previous literature [8,9].But our findings are in contrast with other literature [10].The treatment adherence in the past, presence of family H/o bipolar in the first degree relatives, presence of family $\mathrm{H} / \mathrm{o}$ alcohol dependence in the first degree relatives and current nicotine dependence between the two groups was noted and compared. In group A 73.8\% were treatment non adherent whereas, in group B 80\% were treatment adherent. Family H/o bipolar was present in 59.5\% and $41.5 \%$ in group A and B respectively. Family $\mathrm{H} / \mathrm{o}$ alcohol dependence is present in $71.4 \%$ in group $\mathrm{A}$ and $12.2 \%$ in group $\mathrm{B}$ which shows a significant statistical difference. Current Nicotine dependence is present in $76 \%$ in group $\mathrm{A}[11,12,13]$. Mean age of onset of illness in group $\mathrm{A}$ and $\mathrm{B}$ is 23.5 and 23.7 respectively. The mean of the total no.of episodes is 5.69 and 4.9 in group A and B. Both groups do not have a significant difference in the type of episode, no.of suicidal attempts and 


\section{Cross Sectional Study on Characteristics of Bipolar Disorder Association with Alcohol Dependence in A Tertiary Care Center In South India}

total duration of illness. The findings are in contrast to previous literature [14]. The mean age of onset is not significantly different between the two groups. This may be due to the fact that we have included patients only with bipolar disorders who have subsequently developed alcohol dependence. Patients in group A have more number of hospitalisations (mean 3.98) and longer episodes (mean 5.07 months) than group B, whereas group B has longer remission period than group $A[15]$.The mean scores of YMRS and positive subscale of PANSS for group $\mathrm{A}$ is higher than group B i. e) group A have severe manic symptoms and psychotic symptoms. Insight and functioning are low for group A than group B and patients in group A show more violence and aggression when compared to group B. But HAMD and suicidal intent score doesn't show any significance [16]. The correlation between the severity of alcohol dependence and the severity of psychotic and mood symptoms within group A. There is a significant positive correlation between SADD scores and YMRS scores and aggression scores. There is a significant negative correlation between SADD score and insight. These findings imply that increase in severity of alcohol dependence leads to increase in severity of BPD. There are very few studies on severity of alcohol dependence and the severity of mood symptoms are compared till date[17]. The treatment response between the two groups at the end of 2 weeks after hospitalisation is compared. The difference between the scores at baseline and at 2 weeks is calculated and the mean of the difference is compared between the 2 groups. A significant difference is found showing that manic symptoms and psychotic symptoms respond better in group $B$ than in group $A[18]$.We have observed alcohol dependence in bipolar can be the risk factor of poor treatment adherence, positive family $\mathrm{H} / \mathrm{o}$ bipolar and positive family $\mathrm{H} / \mathrm{o}$ alcohol dependence in first degree relatives. The presence of alcohol dependence could not predict significantly the severity of symptoms.

\section{CONCLUSION}

Increase in severity of alcohol dependence associated increase in severity of BPD. The presence of alcohol dependence has more influence on the severity of illness in bipolar disorder rather than on the course of illness.

Acknowledgement: The authors are also grateful to authors, editors and publishers of all those articles, journals and books from where the literature for this article has been reviewed and discussed.

\section{Conflict of Interest: NIL}

\section{REFERENCES}

1. Regier DA, Farmer ME, Rae DS, Locke BZ, Keith SJ, Judd LL, Goodwin FK. Comorbidity of mental disorders with alcohol and other drug abuse. JAMA. 1990; 264:2511-8.

2. Kessler RC, McGonagle KA, Zhao S, Nelson CB, Hughes M, Eshleman S, Wittchen $\mathrm{H}-\mathrm{U}$, Kendler KS. Lifetime and 12-month prevalence of DSM-IIIR psychiatric 
disorders in the United States. Results from the National Comorbidity Survey. Arch Gen Psychiatry. 1994; 51:8-19.

3. Ishan M Salloum and Michael E. The impact of substance abuse on the course and treatment of bipolar disorder. Bipolar disorders. 2000; 2; 269-280.

4. Brown SA, Schuckit MA. Changes in depression among abstinent alcoholics. J Stud Alcohol. 1988; 49:412-417.

5. Nakamura MM, Overall JE, Hollister LE, Radcliffe E. Factors affecting outcome of depressive symptoms in alcoholics. Alcohol Clin Exp Res. 1983; 7:188-193.

6. Keck PE Jr,McElroySL,Strakowski SM, West SA, Sax KW, Hawkins JM, Bourne ML, Haggard P.12-month outcome of patients with bipolar disorder following hospitalization for a manic or mixed episode. Am J Psychiatry 1998; 155: 646-52.

7. Sheehan DV, Lecrubier Y, Sheehan KH, Amorim P, Janavs J, Weiller E, Hergueta T, Baker R, Dunbar GC. The Mini-International Neuropsychiatric Interview (M.I.N.I.): the development and validation of a structured diagnostic psychiatric interview for DSM-IV and ICD-10. J Clin Psychiatry. 1998;59 Suppl 20:22-33; 34-57.

8. James R. Morrison. Bipolar Affective Disorder and Alcoholism. American Journal of Psychiatry. 1974; 131: 1130-1133.

9. Agarwal ML. Singh G. Socio demographic variables in unipolar and bipolar illness. Indian J. Psychiatry. 1982; 24: 155-158.

10. P.N.Suresh Kumar, S.S. Raju. The impact of substance abuse comorbidity on psychopathology and pattern of remission in mania. Indian Journal of Psychiatry. 1998; 40(4): 357-63.

11. Kosten TR, Kosten TA. New medication strategies for comorbid substance use and bipolar affective disorders. Biol Psychiatry 2004; 56: 771-7

12. Grant BF, Stinson FS, Dawson DA, Chou SP, Dufour MC, Compton W, Pickering RP, Kaplan K.Prevalence and co-occurrence of substance use disorders and independent mood and anxiety disorders: results from the National Epidemiologic Survey on Alcohol and Related Conditions. Arch Gen Psychiatry. 2004; 61: 807-16.

13. Feinman JA, Dunner DL. The effect of alcohol and substance abuse on the course of bipolar affective disorder. J Affect Disord.1996;37:43-9.

14. Stephen M. Strakowski, Susan L. McElroy, Paul E. Keck Jr, Scott A. West The effects of antecedent substance abuse on the development of first-episode psychotic mania Journal of Psychiatric Research.1996;30:59-68.

15. Susan L. Mc Elroy et al. Axis I Psychiatric Comorbidity and its Relationship to Historical Illness Variables in 288 Patients with Bipolar Disorder.Am J Psychiatry. 2001; 158: 420-426.

16. S Pini, L Dell'Osso, C Mastrocinque, G Marcacci, APapasogli, S Vignoli, S Pallanti and G Cassano. Axis I comorbidity in bipolar disorder with psychotic features. The British Journal of Psychiatry.1999; 175: 467-471.

17. Young RC, Biggs JT, Ziegler VE, Meyer DA.A rating scale for mania: reliability, validity and sensitivity. Br J Psychiatry.1978; 133 (5): 429-35. 
18. Goldberg JF, Garno JL, Leon AC, Kocsis JH, Portera L. A history of substance abuse complicates remission from acute mania in bipolar disorder. J Clin Psychiatry. 1999; 60: 733-40.

\section{TABLES}

Table-1: Comparison of continuous illness parameters among two groups(independent ttest)

\begin{tabular}{|l|l|l|l|l|l|l|l|}
\hline & \multicolumn{2}{|c|}{ Group A } & \multicolumn{2}{c|}{ Group B } & t value & $\begin{array}{c}\text { p } \\
\text { value }\end{array}$ & \multicolumn{1}{c|}{$\begin{array}{c}\text { 95\% } \\
\text { C.I }\end{array}$} \\
\hline & Mean & S.D & Mean & S.D & & & \\
\hline $\begin{array}{l}\text { Age of } \\
\text { onset of BPD }\end{array}$ & 23.38 & 5.84 & 26.76 & 10.23 & -1.84 & 0.071 & -7.04 to 0.29 \\
\hline $\begin{array}{l}\text { Total no. of } \\
\text { episodes }\end{array}$ & 5.69 & 3.52 & 4.93 & 3.23 & 1.03 & 0.76 & -0.71 to 2.24 \\
\hline Manic episodes & 3.52 & 2.23 & 3.40 & 2.48 & 0.24 & 0.81 & -0.91 to 1.16 \\
\hline $\begin{array}{l}\text { Depressive } \\
\text { episodes }\end{array}$ & 2.07 & 1.73 & 1.86 & 1.22 & 0.64 & 0.52 & -0.46 to .89 \\
\hline Mixed & 0.11 & 0.39 & 0.44 & 0.73 & -1.36 & 0.21 & -0.9 to .23 \\
\hline $\begin{array}{l}\text { Duration of } \\
\text { longest } \\
\text { episode(months) }\end{array}$ & 5.07 & 1.78 & 3.32 & 2.29 & 3.9 & $.001^{*}$ & 0.86 to 2.64 \\
\hline $\begin{array}{l}\text { Total duration } \\
\text { of BPD (yrs) }\end{array}$ & 12.53 & 8.74 & 11.76 & 7.83 & 0.42 & 0.67 & -2.85 to 4.40 \\
\hline $\begin{array}{l}\text { Longest } \\
\text { remission period } \\
\text { (yrs) }\end{array}$ & 2.56 & 1.87 & 6.24 & 6.16 & -3.59 & $0.001^{*}$ & -5.76 to -1.62 \\
\hline $\begin{array}{l}\text { Total no. of life } \\
\text { time suicidal } \\
\text { attempts }\end{array}$ & 1.63 & 1.94 & 1.38 & 1.54 & .47 & 0.64 & -0.84 to 1.35 \\
\hline $\begin{array}{l}\text { Total no. of } \\
\text { hospitalisations }\end{array}$ & 3.98 & 2.61 & 2.83 & 1.95 & 2.25 & $0.03^{*}$ & 0.13 to 2.16 \\
\hline
\end{tabular}

Table-2: Correlation of Severity of alcohol dependence with symptom severity in Group A

\begin{tabular}{|c|c|c|c|}
\hline Scores at baseline & $\mathbf{N}$ & $\begin{array}{c}\text { Pearson's } \\
\text { correlation } \\
\text { coefficient (r) }\end{array}$ & $\begin{array}{c}\text { p value } \\
\text { significance 2 tailed }\end{array}$ \\
\hline YMRS & 32 & 0.67 & $0.02^{*}$ \\
\hline HAMD & 13 & 0.55 & 0.57 \\
\hline Positive subscale PANSS & 32 & 0.61 & $0.03^{*}$ \\
\hline F.A.S.T & 42 & 0.57 & $0.04^{*}$ \\
\hline ITAQ & 42 & -0.49 & $0.01^{*}$ \\
\hline OAS & 32 & 0.46 & 0.007 \\
\hline BSI & 9 & -0.27 & 0.94 \\
\hline
\end{tabular}

$* \mathrm{P}<0.05$ are considered significant 
Cross Sectional Study on Characteristics of Bipolar Disorder Association with Alcohol Dependence in A Tertiary Care Center In South India

Table-3: Comparison of symptom scores among two groups using independent t-test

\begin{tabular}{|l|l|l|l|l|l|l|l|l|l|}
\hline & \multicolumn{3}{|c|}{ Group A } & \multicolumn{5}{c|}{ Group B } & \multicolumn{1}{c|}{ t } \\
value & palue & Df \\
\hline & N & Mean & S.D & N & Mean & S.D & & & \\
\hline YMRS base & 32 & 38.25 & 5.09 & 30 & 29.53 & 5.3 & 6.57 & $0.001^{*}$ & 60 \\
\hline YMRS - 2wks & 32 & 32.53 & 5.56 & 30 & 20 & 3.88 & 10.21 & $0.001^{*}$ & 60 \\
\hline HAMD base & 13 & 33.62 & 3.78 & 11 & 31.91 & 4.93 & 0.96 & 0.35 & 22 \\
\hline HAMD - 2wks & 13 & 28.46 & 4.19 & 11 & 24.64 & 5.84 & 1.86 & 0.09 & 22 \\
\hline $\begin{array}{l}\text { PANSS positive } \\
\text { subscale base }\end{array}$ & 32 & 23.09 & 2.36 & 30 & 19.6 & 3 & 5.11 & $0.02^{*}$ & 60 \\
\hline $\begin{array}{l}\text { PANSS positive } \\
\text { subscale - 2wk }\end{array}$ & 32 & 18.88 & 2.48 & 30 & 13.67 & 2.63 & 8.01 & $0.03^{*}$ & 60 \\
\hline F.A.S.T. base & 42 & 47.12 & 10.12 & 41 & 32.83 & 8.88 & 6.82 & $0.04^{*}$ & 81 \\
\hline $\begin{array}{l}\text { F.A.S.T. }-2 \\
\text { wks }\end{array}$ & 42 & 40.02 & 10.13 & 41 & 23.15 & 7.02 & 8.79 & 0.06 & 81 \\
\hline ITAQ base & 42 & 10.79 & 3 & 41 & 13.24 & 1.86 & -4.46 & $0.04^{*}$ & 81 \\
\hline ITAQ - 2wks & 42 & 14.29 & 2.97 & 41 & 18.39 & 1.70 & -7.69 & 0.06 & 81 \\
\hline OAS base & 32 & 28.81 & 4.27 & 30 & 13.6 & 3.76 & 18.55 & $0.04^{*}$ & 60 \\
\hline OAS - 2wks & 32 & 24.19 & 4.23 & 30 & 9.03 & 1.47 & 19.03 & $0.03^{*}$ & 60 \\
\hline BSI base & 9 & 16.22 & 2.33 & 6 & 17 & 1.89 & -0.68 & 0.51 & 13 \\
\hline BSI - 2 wks & 9 & 12.44 & 2.74 & 6 & 11.83 & 1.60 & 0.49 & 0.63 & 13 \\
\hline
\end{tabular}

Table-4:Comparison of mean difference in the symptom severity scores at baseline and two weeks between two groups (Paired t test)

\begin{tabular}{|c|c|c|c|c|c|c|c|c|c|}
\hline & \multicolumn{3}{|c|}{ Group A } & \multicolumn{3}{|c|}{ Group B } & \multirow[t]{2}{*}{ t value } & \multirow[t]{2}{*}{ p value } & \multirow[t]{2}{*}{ df } \\
\hline & $\mathbf{N}$ & Mean & S.D & $\mathbf{N}$ & Mean & S.D & & & \\
\hline $\begin{array}{l}\text { YMRS } \\
\text { difference }\end{array}$ & 32 & 5.71 & 1.63 & 30 & 9.53 & 2.67 & -6.82 & $0.02^{*}$ & 60 \\
\hline HAMD diff & 13 & 5.15 & 1.46 & 11 & 7.27 & 1.20 & -2.90 & $0.08^{*}$ & 22 \\
\hline $\begin{array}{l}\text { PANSS } \\
\text { positive } \\
\text { subscale diff }\end{array}$ & 32 & 4.21 & 1.00 & 30 & 5.93 & 1.61 & -5.04 & $0.01^{*}$ & 60 \\
\hline F.A.S.T diff & 42 & 7.09 & 2.73 & 41 & 9.68 & 4.06 & -3.41 & 0.06 & 81 \\
\hline ITAQ diff & 42 & -3.5 & 1.15 & 41 & -5.1 & 1.08 & 6.69 & 0.08 & 81 \\
\hline OAS diff & 32 & 4.62 & 1.12 & 30 & 4.56 & 2.76 & 0.11 & 0.91 & 60 \\
\hline BSI diff & 9 & 3.77 & 1.30 & 6 & 5.16 & 2.48 & -1.42 & 0.18 & 13 \\
\hline
\end{tabular}

How to cite this article: B. Bhuvaneshwaran, R. Kumar (2017). Cross Sectional Study on Characteristics of Bipolar Disorder Association with Alcohol Dependence in A Tertiary Care Center In South India. International Journal of Indian Psychology, Vol. 5, (1), DIP:18.01.048/20170501, DOI:10.25215/0501.048 